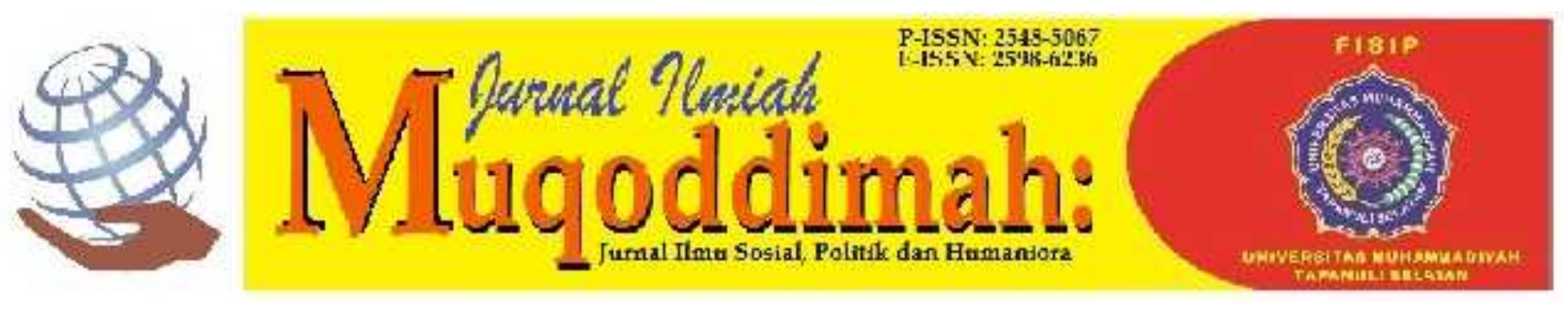

\title{
Masa Depan Media Massa di Era Digital
}

\author{
Yofiendi Indah Indainanto
}

\author{
Magister IImu Komunikasi, Universitas Diponegoro \\ Jl. Erlangga Barat 7 No. 33, Semarang, Jawa Tengah, Indonesia
}

yofiendi@gmail.com

\begin{abstract}
Abstrak
Internet memberikan perubahan praktik dan teoritik dalam melihat perkembangan media massa menghadapi era digital. Perubahan gaya transaksional media ke arah interaksi membuat media terus mengoktimalkan terlibatnya pembaca dalam memproduksi konten dan memanfatakan media-media baru pendukung produksi. Tidak sedikit media merubah cara kerja, produksi konten, bisnis dan struktur organisasi media agar mampu bersaing. Praktik jurnalisme digital di Indonesia terus berupaya membangun iklim media yang disukai pembaca, stabil dan dinamis. Tujuan penelitian ini menggambarkan pola-pola media digital dalam menghadapi era distrupsi media dengan fokus perhatian pada perubahan konten dan model bisnis. Metode yang digunakan diskriptif kualitatif dengan pendekatan studi literatur. Hasil penelitian menemukan, perkembangan teknologi digital melahirkan media online baru dan memaksa media lama melakukan konvergensi. Media mulai melakukan perubahan-peruban mulai dari tampilan dan distribusi konten. Konten media sangat dipengaruhi isu dan interkasi yang terjadi dimedia sosial. Media menghadirkan sengmentasi kusus untuk pembaca dengan mulai mencoba berbagai altertatif konten mulai postioning dan monetisasi yang merubah cara bisnis media diera sekarang.
\end{abstract}

Kata kunci:Internet, Media Online, Bisnis Media, Journalistik

\begin{abstract}
The internet provides practical and theoretical changes in viewing divelopmente the mass media that meet the digital age. Changing the transactional style of the media toward interaction makes the media continue to include the participation of readers in producing content and utilizing new media supporting production. Not a few media changed the way work, content production, business, and media organizational structure to be able to compete. The practice of digital journalism in Indonesia continues to build media that is supported by readers, stable, and dynamic. The purpose of this research is to discuss the patterns of digital media in the discussion of the era of media distribution with a focus on changing content and business models. The method used is descriptive qualitative using the study of literature. The results of the study found that the development of digital technology, accepting new online media, and supporting old media converged. The media began to make changes starting from the appearance and distribution of content. Media content is very problem and interaction that occurs in social media. The media presents tangled segmentation to the reader by starting to search for various contents starting from positioning and monetization which are changing the way the media business is perceived now.
\end{abstract}

Keywords: Internet, Online Media, Media Business, Journalistic 


\section{PENDAHULUAN}

Ketergantungan menggunakan teknologi komunikasi telah menjadi bagian penting keberlangsungan peradaban manusia dimassa depan. Perubahan individu mendapatkan informasi melalui media massa seperti suarat kabar, majalah, buku, televisi, dan radio. Era media konvensional memberikan pengaruh penting dalam memberikan informasi. Adanya teknologi membuat sistem jurnalisme bergeser, mulai berita muncul di platform online yang berdampak bagi organisasi media berita, yang memengaruhi lalu lintas, pendapatan audiens, dan praktik media yang sangat epistemik karena mereka beradaptasi untuk memproduksi konten untuk platform digital seperti sebagai Facebook dan Twitter (Ekstrom dan Westlund, 2019) dalam (Eldridge, Hess, Tandoc, \& Westlund, 2019:397).

Ketika teknologi yang didiskusikan dipekerjakan, justru menjadi ancaman bagi keberlangsungan hidup dengan merusak individualitas, otonom dan fondasi masyarakat bebas (Sætra, 2019:1), hal itu yang menjadi probelematikan. Infrastruktur teknologi nantinya memiliki kencenderungan dari lanskap berita digital untuk menunjukkan distribusi ke arah pola penggunaan yang relatif homogen, meskipun preferensi tampaknya berbeda, kemudian memengaruhi penggunaan (Taneja, Wu, \& Edgerly, 2018:1794). Membahas media massa tidak terlepas persoalan bagaimana media memproduksi konten yang akan memberikan pengaruh bagi audiens, melainkan media bertahan menghadapi pasar. Media yang tidak memapu menghadapi tantangan jaman akan tenggelam, meskipun iklim bisnis dan dukungan organisasi mampu memberikan jaminan.

Teknologi membantu jurnalisme sebagai sistem cerdas yang mampu menemukan pola yang mudah terlewatkan oleh persepsi manusia. Namun, akan mampu meningkatkan PHK, personalisasi polarisasi, dan komoditisasi penulisan berita (Carlson, 2015:14). Revolusi teknologi komunikasi tahun 1990-an memberikan babak baru bagi media massa yang ditandai munculnya internet. Awalnya media massa sangat terbantu dengan adanya internet untuk mempermudah kinerja, kini internet pula yang membuat media massa eksistensinya berkurang, sebut Harian Bola yang tutup pada oktober 2015 dan Tabloid Bola 26 oktober 2018.

Menurut Survei Nielsen Consumer \& Media View hingga triwulan ketiga 2017 menyatakan, kebiasaan membaca orang Indonesia telah mengalami pergeseran. Pada 2017, tingkat pembelian koran secara personal hanya sebesar $20 \%$, menurun dibandingkan 2013 yang mencapai 28\% (Https://katadata.co.id). Artianya media konvensional mengalami kemunduran, dan internet memunculkan media baru yang ditandai dengan digitalisasi berbagai konten.

Menurut data Asosiasi Penyelenggara Jasa Internet Indonesia (APJII), Jumlah pengguna internet mencapa 64,8 persen atau dari 264 juta jiwa penduduk Indonesia, sebanyak 171,17 juta telah terhubung internet (Https://tekno.kompas.com). Dalam kacamata bisnis, ini merupakan babak baru media Indonesia dan peluang besar mendatangkan keuntungan. Internal media ditekan untuk meninggalkan logika dominan dan mengubah dinamika penciptaan nilai yang mendasari model bisnis mereka (Evens, Raats, \& von Rimscha, 2017:2), sehingga akan mendatangan nilai inovatif yang disukai. Media online diperkirakan mencapai angka 43.300. hanya 211 media profesional pada 2014, di tahun 2015 menyusut menjadi hanya 168 media online saja pada 2015(JurnalDewanPers, 2017) , sehingga memungkinkan menimbulkan persaingan baru bagi media.

Jurnalisme profesional secara historis dibangun di sekitar dua elemen tekstual dan visual (Coddington, 2015:1), yang memungkinkan setiap jurnalis memiliki kemapuan kusus dalam memproduksi konten. Inovasi media muncul menawarkan tampilan yang memanjakan pembaca. Praktik jurnalis dengan adanya teknologi mengalami perubahan 
baik di isi, cara kerja dan keputusan diruang redaksi.

Jurnalisme digital didefenisikan sebagai praktik-praktik pengumpulan berita, pelaporan, produksi teks dan komunikasi tambahan yang mencerminkan, merespons, dan membentuk logika sosial, budaya dan ekonomi dari lingkungan media digital yang terus berubah (Burgess \& Hurcombe, 2019:365). Artinya pola dan praktik media terus mengalami perubahan.Tujuan penelitian ini menggambarkan pola-pola media digital dalam menghadapi era distrupsi media dengan fokus perhatian pada perubahan konten dan model bisnis. Hal ini menjadi penting, karena media-media di Indonesia sedang mengalami permasalahan yang sama, yaitu berusaha mencari model media, meningkatkan kepercayaan pembaca, membangun iklim bisnis, serta bersaing dengan media sosial yang banyak menarik minat para pengguna internet untuk segementasi hiburan. Dampaknya membuat praktik media terus berubah akibat disrubsi digital.

Penelitian Bob Franklin (2014), The Future of Journalism, memberikan gambaran tentang perkembangan media jurnalistik, serta mengambarkan perubahan praktik dan teori jurnalitik. Penelitan Firdaus Noor(2018) tentang usaha media online Kompas dan Detik yang menghadapi permasalah karakterisitk media online yang mencakup keterbatasan iklan, isu keamanan, pelanggaran kode etik, dan persepsi kualitas media online sebagai media kelas dua dan menyarankan media melakukan inovasi perluasan kanal. Tidak hanya media online yang melakukan perubahan dengan adanya dunia digital. Menurut Saptya \& Permana (2019) yang melihat strategi NETtv dalam menghadapi persaingan menggunakan media sosial (Facebook, Twitter, Instagram, YouTube, LikedIn, dan Google+) serta kanal digital khusus milik mereka, yakni Zulu.id.

Penting melihat bagaimana media membangun model media (bisnis dan konten) ditenggah kelimpahan Informasi yang masyarakatnya lebih percaya berita di media sosial, infrastrukur teknologi yang terbatas, serta audiens yang berbeda generasi. Kedua penelitan diatas telah mengidentifikasi penggunaan media baru sebagai distribusi alternatif menghadapi persaingan.

\section{METODE}

Metode penelitian studi kualitatif dengan pendekatan literatur yang mengambarkan pola praktik media online terus mencari model bisnis mulai dari penggunaan teknologi, perubahan konten dan jurnalis.

Penjelasan literatur dimaksudkan untuk memberikan gambaran komprehensif mengenai media masa yang melakukan perubahan dengan adanya teknologi. Analisis didasari pada aspek gaya kerja jurnalis dan model bisnis.

\section{HASIL DAN PEMBAHASAN \\ Media Sosial Sebagai Pemikat}

Kebebasan berekspresi dengan berbagai bentuk kegunaan, nyatanya membuat media sosial menjadi media yang paling sering digunakan untuk keperluan tertentu seperti menggungah foto, video, cerita keseharian, dan bisnis. Media sosial selalu berkaitan dengan eksisteni pengguna, sehingga memungkinan penggunanya saling terkait, meningkatkan hubungan dan ikatan sosial. Platform media sosial dapat digunakan untuk mempromosikan merek dengan maksud memengaruhi keputusan konsumen, meningkatkan kesadaran merek tertentu (Rambe \& Jafeta, 2017:659).

Berdasarkan data We Are Social awal tahun 2019, sekitar 57\% penduduk Indonesia menggunakan berbagai media sosial dengan angka mencapai 150 pengguna. Youtube menjadi media yang sering diakses dengan 88\% atau 132 juta orang mengakses, disusul Whatsapp 83\% atau 125 juta orang, Facebook 81\%atau 122 juta 
orang, dan Instagram $80 \%$ atau 120 juta orang(Https://www.brilio.net). Artinya media sosial menghadirkan interakasi trafficonline yang tinggi setiap waktunya, hal ini memungkinkan informasi yang ada sangat

Menurut Baidu, (2014) Berkat teknologi baru seperti internet segala kebutuhan manusia dapat dipenuhi. Mulai dari kebutuhan untuk bersosialisasi, mengakses informasi sampai kepada pemenuhan kebutuhan hiburan. Kini, kehadirannya lebih dimanfaatkan sebagai media sosial oleh masyarakat ( Baidu, 2014: 15 dalam Soliha, 2015:2). Melihat karakterisitk media sosial yang menciptakan interaksi dan sarana berbagai virtual membuat media online melirik untuk mengarahkan pengguna media sosial mengunjungi media online. Tidak hanya berlomba dengan jumlah traffic kunjungan, media sosial juga berlomba meningkatkan followers dengan asumi, semakin banyak followes akan semakin tinggi interaksi virtual dimedia online.

Praktik seperti ini banyak dilalukan media-media online besar di Indonesia seperti Kompas.com, Detik.com, Republikaonline.com, Tribunnews.com, Idntimes.com dan lainnya. Hampir sebagian besar media menggunakan media sosial seperti Facebook, Twitter, Youtube, dan Instagram. Berbagi Link dengan caption yang membuat orang penasaran, judul berita yang diikuti dengan foto membuat orang, secara tidak langsung akan mengclik link yang ada dipositngan. Cara seperti ini sangat efektif menarik pembaca pasif yang menggunakan media sosial hanya untuk berhubungan dengan orang lain. Saat berada disitus web berita, penyedia media selalu memberikan hastag atau tagar di akir berita yang terhubung dengan berita lain sejeninnya. Contohnya dalam berita dari news.detik.com tentang "1.000 Personel Gabungan TNI-Polri Pertebal Pengamanan Kota Sorong", diakhir berita berisi pemberitahuan tentang isu yang terkait dengan berita utama seperti“ \#sorong, \#papua_barat, \#papua \#rusuh di papua \#tni \#polri". Hal senada dilakukan di media viva.co.id, seperti dalam berita "Bye Jakarta, Ibu Kota Negara Pindah ke Kalimantan", yang terhubung dalam tagar “ibu kota pindah, ibu kota luar jawa, ibu kota baru, kalimantan". Dalam berita tampilan, ditengah berita juga terdapat berbagai judul berita yang relevan dengan berita. Media online di Instagram, menggunakan story yang berdurasi waktu untuk menampilkan berita yang telah terbit, namun juga tetap menggunakan postingan dengan berbagai desain penyampaian bisa berupa poin penting berita yang sifatanya bersambung, jika ingin menyelesaikan berita harus mengunjungi website. Begitupula di Story yang menampilkan berita singkat yang terkadang berupa lead berita. Cerita Instagram yang singkat, dinamis, dan interaktif sangat efektif dan cepat untuk tujuan jangka pendek lainnya(Belanche, Cenjor, \& Pérez-Rueda, 2019:87). Praktik di Istagram tidak jauh berbeda dengan di Facebook, namun berbeda dengan di Youtube, yang menampilkan berita menggunakan gambar dan suara dilengkapi diskripsi video seperti yang ada dichanel youtubeTribunnews.com. Melihat posingan di youtube, Tribunnews.com tidak ada arah untuk menggunjungi situs tertentu untuk kelengkapan berita, artinya pengguna tidak diarahakan secara langsung untuk menyaksikan berita.

Konten media baru dibuat dengan cara mengubah isi tidak sesuai dengan media seluler. Kenyataannya, wartawan telah menggunakan media sosial sebagai alat yang berguna untuk mencari item berita (Kim \& Kim, 2018:341). Penetitian (Weaver \& Willnat, 2016) pada wartawan Amerika menemukan, jurnalis menggunakan media sosial sebagai alat pengumpul informasi, memeriksa berita media lain, mendapatkan berita terkini, mewawancari narasumber, memvalidasi informasi. Media sosial berdampak baik 
pada pekerjaan wartawan dan wartawan lebih bertanggung jawab kepada publik. Newsroom dalam ruang redaksi menjadikan info terkini dimedia sosial dijadikan bahan yang nantinya di framing dengan kepentingan media.

Dalam penelitan Maybi dan Irwansyah yang melihat media sosial twitter dengan fokus pembahasan tentang "Pengaruh Trending Topics Politik sebagai Reversed Agenda-Setting dan Haluan Politik Pemilik Terhadap Berita Politik di Televisi,", mendapati hasil pengaruh trending topics media sosial tetaplah signifikan. Pengaruh trending topics politik menjadi penyeimbang terhadap tekanan haluan politik pemilik yang dijadikan untuk mengurangi intervensi dari haluan politik pemilik dalam memporoduksi informasi yang mempengaruhi agenda publik. Dengan demikian, media sosial mampu memberikan pengaruh dalam proses produksi diruang redaksi dan mampu mempengaruhi kepentingan media.

Begitupula penelitian Vivi Ocktaviani Tentang "Media Sosial sebagai Sumber Berita di Detikcom", mendapatkan hasil . informasi yang menarik di bicarakan di media sosial layak diberitakan dengan mengkonfirmasi berita. Detikcom menganggap sudah menjadi tugas media massa untuk menelusuri informasi viral yang ada di media sosial, memberikan suatu fakta dengan konfirmasi dan verifikasi untuk mengungkapkan kebenaran informasi tersebut dan disebarluaskan kepada khalayak melalui pemberitaan yang dapat dipertanggungjawabkan. Dengan hasil itu, informasi dimedia sosial tidak kalah penting dengan berita dilapangan. Dalam praktiknya media online selalu melihat perkembangan dimedia sosial agar tidak tertinggal informasi yang sedang diperbincangan para nitizen. Seperti yang dilakukan, Idntimes.com memanfatakan berita trending di twitter untuk bahan berita seperti dalam berita " "\#SaveSpiderMan, Fans Ngamuk Tak Rela Spider-Man Direnggut dari Marvel", yang kesemua itu bersumber dari perbincangan nitizen kemudian diolah menjadi berita. Senada dengan idntimes.com, kumparan.com juga mengangkat berita serupa dengan judul "\#SaveSpiderMan, Fans Kecewa Spider-Man Tak Lagi Gabung MCU".

Selain itu, positingan orang berpengaruh ikut menjadi bahan berita, seperti postingan Prabowo yang menanggapi komentar netizen di Twitter dalam berita newsdetik.com ", dalam penjelasan berita turut memasang bentuk komentar nitizen, "Pagi pak @prabowo..Pak kenapa suka buka baju si? Emang gak takut masuk angin? (-) [," tulis akun tersebut. Prabowo pun menjawab pertanyaan tersebut. Dia mengaku terbawa oleh antusiasme pendukung saat membuka bajunya. "Refleks aja terbawa suasana yang sangat bersemangat. Wajarlah," jawab Prabowo", hal itu menjadi kronologi berita. Dalam nilai berita salah satunya adalah tentang ketokohan yang membuat berita itu bernilai. Ketokohan bisa berupa public figure seperti tokoh politik, kepala negara, artis, akademisi dan jabatan struktural lainnya, wajar setiap aktifitas yang berkaitan dengan tokoh sangat menarik dijadikan berita meskipun dari berbagai sumber. Dengan bantuan Micro-blogging seperti Twitter memperluas kemampuan berkomunikasi (Hermida, 2010:299).

\section{Transformasi Konten}

Media online tidak terlepas bagaimana membangun kepercayaan pembaca dan membuat pembaca menjadikan media tersebut menjadi bahan refrensi. Strategi awal yang dilakukan media adalah dengan penggunaan judul yang membuat penasaran atau clickbait. Clikbait menjadi penting dalam era digital sebagai daya tarik berita. Hasil 
penelitian B García Orosa, S Gallur Santorun, X López García (2017) dengan judul "Use of clickbait in the online news media of the 28 EU member countries", yang dilakukan di 28 media online di Uni Eropa dampak utama penggunaan clickbait adalah judul berita telah berubah dari memberikan informasi menjadi elemen penting untuk membujuk pembaca agar tetap berada di halaman (website) selama mungkin. Hasilnya klik tidak melalui konten berkualitas, melainkan dalam hampir separuh kasus, melalui tajuk utama halaman depan yang menarik, provokatif, dan sensasional yang bertujuan mengeksploitasi keingintahuan pengguna.

Penelitian lain dilakukan Yayat D. Hadiyat yang melihat fenomena clikbait di media Indonesia. Hasil menunjukan secara umum, penggunaan judul artikel clickbait banyak digunakan oleh media-media online untuk menarik minat pembaca dengan mengusik rasa penasaran yang timbul akibat adanya kesenjangan informasi antara apa yang pembaca ketahui dan apa yang ingin pembaca ketahui. Seperti dalam berita Tribunnews.com dalam berita "Heboh Calon Menteri Muda Jokowi, Ini 4 Menteri Muda dari ...", dan "Kaum Milenial Heboh Saat Melihat Reaksi Prabowo Ditanya ...",yang mengajak pembaca mengklik berita. Rasa penasaran yang didapat dari judul yang bersambung memberikan dorongan bagi pembaca untuk mencari tahu isi berita.

Perubahan gaya penyajian konten juga terjadi dalam isi media. Media online cenderung mementingkan realtime sehingga beritanya mengulas hanya sekilas dengan jenis berita berupa straightnews. Dalam satu peristiwa akan menjadi banyak berita didalam media online. Karakterisitk seperti ini dimaksudkan agar pembaca mengklik berita lain sehingga menimbulkan keuntungan dari interaksi hasil klik pembaca. Dalam prspektif pembaca, berita yang mendalam akan menimbulkan kebosanan ketika membaca menggunakan perangkat elektronik. Contohnya yang dilakukan Tribunews.com, dalam pristiwa kerusuhan di Papua Barat dengan engel seperti "Kata Wagub Papua Barat, Ada Pihak Tertentu yang Menunggangi Insiden Kerusuhan di Fakfak", "Penjelasan Polisi Terkait Penyebab Kerusuhan di Fakfak", "Rusuh di Fakfak Dipicu Pengibaran Bendera Bintang Kejora?", "Massa Mulai Lempari Gedung DPRD Mimika, Polisi Pukul Mundur Demonstran, Situasi Kembali Terkendali”, "Aparat Pukul Mundur Massa, Situasi di Mimika Terkendali”, berita-berita itu memberikan pengaruh besar dalam rentetan berita pada tanggal 21 agusutus yang memenuhi media diberbagai paltfom media Tribunnews.com, dengan terget pembaca akan tertarik dan meningkatkan interkasi trafik kujungan web.

Selain itu, media online selalu berlomba-lomba membuat daya tarik agar ingatan pembaca akan sebuah peritiwa melekat dan menjadikan berita tersebut tetap menjadi refrensi informasi. Karakteristik media online yang menampilkan logika jangka pendek dalam pemberitaan dengan ciri berita ringkas, berkelanjutan dan mementingkan jumlah views menghadirkan peluang baru untuk menolak logika seperti itu. Dalam penelitian Suluh Gembyeng Ciptadi \& Ade Armando dengan judul "Upaya Agensi Melawan Logika Jangka Pendek Jurnalisme Daring: Studi Kasus Tirto.id", menemukan bahawa bahwa Tirto.id menampilkan berita panjang, mendalam, cover both sides, dan penuh data merupakan bentuk-bentuk resistensi yang dilakukan Tirto. Upaya resistensi dilakukan untuk mewujudkan visi membangun peradaban baru literasi daring di Indonesia. Dalam mendukung pemberitaan itu, Tirto.id menyertakan infografis untuk mendukung berita. Infografis menghadirkan poin-poin berita yang membuat pembaca mengetahui rentetan kronologi sebuah berita. 
Hasil penelitan Riyanti Hayuning Pratiwi dan Ferry Darmawan yang melihat "Infografis Sebagai Pendukung Berita In-depth Dalam Situs Berita Online" menemukan, data yang diinput memuat nilai berita, Kedalaman informasi yang disuguhkan infografis in-depth dirasa masih kurang jika dibandingkan dengan kedalaman berita itu sendiri, namun infografis dan isinya saling melengkapi, dan penggunaan infografis dalam sebuah berita in-depth tidak lain sebagai penarik perhatian pembaca. Artinya infografis telah menjadi bagian penting dari isi berita yang disajikan dalam bentuk poin-poin penting. Dalam membaca berita in-depth membutuhkan waktu, dan pemahaman, sehingga hadirnya infografis memberikan warna baru bagi pembaca dalam memahami isi berita untuk mengetahui poin nilai berita. Langkah seperti ini nyatanya sangat efektif menarik pembaca, terlebih infografis dijadikan daya tarik berita dengan mempositing ke media sosial yang terhubung link berita. Ada juga media online menyajikan berita dalam bentuk video teks yang memungkinkan pembaca tidak perlu menggeser untuk melanjutkan membaca.

\section{Menerka Bisnis Media Online}

Perubahan demografi kebiasaan komsumsi pada era sekarang memberikan sebuah tantangan baru bagi media. Munculnya media yang berkarakter startup memberikan peta persaing bagi media yang sistem group atau yang dikenal "anak kandung", sehingga segmentasi semakin beragam dan konsumen semakin selektif memilih yang disukai. Karakter audies yang berkuasa dalam memilih konten, mendorong media online menampilkan perubahan yang disesuaikan dengan kebiassan terget audines. Dalam mendistribusikan konten, tantangan dalam mempertahankan dan membangun kembali hubungan pelanggan yang telah terfragmentasi oleh berbagai platform tanpa akhir dan perangkat, sehingga media harus menawarkan perubahan. Setidaknya media online saat ini sedang membangun model, Kolaborasi, positioning (membentuk identitas media), segementasi, dan monetezing. Poin pentingnya bisnis berita online adalah dengan menawarkannya secara gratis pada titik konsumsi, tetapi didukung oleh iklan (Fletcher, Nielsen, Fletcher, \& Nielsen, 2016:3). Kolaborasi media online di Indonesia banyak diperaktekan dalam bentuk kerjasaam baik antar media maupun diluar media, dengan meningkatkan interaksi yang terlibat dalam asas manfaat.

Salah satu bentuk media yang melakukan ini adalah Kumparan.com, dengan Majalah bisnis SWA. Berita yang dihasilkan majalah SWA dapat di akses secara online dikanal kumparan.com (Https://kumparan.com). Artinya konsep menggabungkan dunia offline dan online atau yang biasa dikenal situs media online hybrid akan mampu meningkatkan interaksi pembaca. Selain itu, kolaborasi dengan Pantura Post (Panturapost.com) yang mengkolaborasikan antara media online dan media sosial membuat kumparan.com konsisten dalam memproduksi konten berkualitas (Https://kumparan.com) Kolaborasi juga dapat dilakukan di media sosial.

Positioning menjadi hal penting dalam memberikan perbedaan yang menangkap peluang. Media berusaha mengemas konten, tampilan semenarik mungkin agar memberikan identik. Identik tersebut bisa berupa pemilihan warna, variasi konten, gaya penulisan. Seperti yang dilakukan mojok.co, (Https://mojok.co/daf/esai/jika-googlemendadak-hilang-dari-dunia-ini-karena-digugat-donald-trump/,) menampilkan berita dalam bentuk softnews, menampilkan gambar animasi, sehingga ketika orang mengenal mojok.co akan memberikan kesan dan identik tertentu dalam pikiran. Begitu juga yang 
dilakukan media tirto.id, memberikan posioning konten mendalam berbeda dengan media online lainya. Selain itu, posisioning iklan sangat berpengaruh terhadap karakter media. media yang iklanya banyak akan menimbulkan rasa tidak nyaman sehingga kesan ini melekat. Segmentasi berkaitan dengan bagaimana media membagi teget pembaca.

Berdasarkan data Asosiasi Penyelenggara Jasa Internet Indonesia (APJII) menyebut Pengguna internet berdasarkan umur tahun 2018, generasi $Z$ usia 15-19 tahun mempunyai penetrasi paling tinggi mencapai $91 \%$, Tertinggi kedua ada pada kelompok usia 20-24 tahun dengan 88,5\% . Secara berurutan kemudian, usia 25-29 tahun $(82,7 \%), \quad 30-34$ tahun $(76,5 \%), \quad 35-39$ tahun $(68,5 \%)$ (Https://beritagar.id/artikel/berita/generasi-z-pengguna-internet-terbesar-di-indonesia,). Artinya Generasi $Z$ akan menjadi pembaca aktif dimasa depan, karena penggunaan aktif internet. Sehingga media online yang akan bertahan harus mampu mengsegmentasi pembaca berdasarkan generasi. Membaca karakter tren konsumsi konten sekarang, pra generasi milenial banyak mendapatkan hiburan di media sosial seperti Youtube.com, Sehingga media online harus memberikan konten dengan segmentasi kusus. Seperti yang dilakukan www.kapanlagi.com, konsen menampilkan berita tentang gaya hidup yang disukai anak muda. Monetezing, berkaitan bagiamana konten mampu mendapatkan keuntungan. Namun masalah yang muncul disini, bagaimana karakterisitk masyarakat Indonesia lebih menyukai konten gratis dibanding berbayar.

Dilematika ini, memberikan permasalahan baru saat pemilik media tidak membatasi para pembaca untuk mengakses situs web, karena semakin tinggi pembaca akan mempengaruhi iklan yang akan memberikan keuntungan, membatasi akses, sama halnya mengilangkan pembaca yang akan memilih konten geratis. Sehingga mediamedia menjadikan konten untuk mendatangkan iklan. Tingginya pembaca dijadikan dasar untuk mendatangkan iklan atau dalam bahasa Vincent Moskow Komodifikasi. Komodifikasi terjadi terhadap konten, audien/penonton, dan pekerja. Komodifikasi konten dilakukan agar dapat menarik perhatian penonton, sehingga terkait bagaimana konten tersebut digunakan untuk pemosisian periklanan (Indah:2015). Namun, ditengah banjir informasi, konsep konten berbayar ( Paywall) memberikan warna baru bagi para pembaca yang menginginkan kenyamanan. Pembaca nantinya akan selektif dalam mengkosumsi konten sesuai kebutuhan. Personalisasi konten akan menjadi prioritas penting bagi para penyendia konten. Paywalls dibangun dengan kecepatan tinggi, telah membuat dominasi industri sebelumnya bahwa berita harus tetap gratis ,tetapi media perlahan mulai kesulitan akibat konten gratis (Franklin Bob, 2014:483).

Monetisasi Media Indonesia terhambat akibat kebiasan media memberikan konten geratis dan kebiasan orang Indonesia yang menyukai sesuatu yang geratis. Namun tingginya penetrasi pengguna internet menjadikan iklan di media online akan semakin bertambah, aritnya rasa nayaman pembaca akan berkurang. Praktik konten berbayar di Indonesia dilakukan dalam bentuk epeper dari media konvesional seperti, Kompas (https://gerai.kompas.id/), Tempo (https://koran.tempo.co/), Republika (https://epaper.republika.co.id/). Media-media di Indonesia perlu belajar dari kesuksesan The New York Times(https://www.nytimes.com)bagaimana membangun konten berlangganan?. Media seperti USA Today, Washington Post dan Fairfax Media telah 
memperaktekan konten berlangganan, dengan memberikan konten premium kepada pembaca yang berbeda dengan konten geratis.

Resiko Paywall adalah kehilangan para pembacanya seperti yang dialami media Times yang kehilangan hampir 90\% (www.theguardian.com). Sehingga media-media sekarang berusaha mencari formula bisnis diera digital. Faktanya Internet merubah sikap pengguna tidak akan membayar untuk konten online, karena informasi bisa didapat secara gratis ((J. H. \& N. Thurman, 2007:211). Hasil penelitian Merja Myllylahtia (2014) yang melihat pengaruh paywall terhadap pendapatan perusahaan media di Amerika Serikat, Inggris, Slovakia, Slovenia, dan Polandia, Australia, Selandia Baru, dan Finlandia menemukan, harga paywalls menurun karena perusahaan berita berjuang untuk pelanggan dan pendapatan digital baru. konten berita online berbayar tidak cukup besar untuk menjadikan paywalls model bisnis yang layak dalam jangka pendek. Itu membuat media akan kehilangan pembaca jika terus memaksakan. Situs media web berita sulit menerapkan paywall jika mereka menawarkan konten berita atau topik yang dapat dengan mudah ditemukan orang di tempat lain (Brandstetter \& Schmalhofer, 2014:501). Artinya media harus memberikan poin lebih terhadap berita yang ditampilkan. Melihat para wartawan di Indonesia, mereka disibukan memenuhi target berita setiap harinya agar dapat menarik pembaca. Beban itu bertambah ketika era konvergensi media yang membuat media bekerja untuk memenuhi berbagai platfrom media seperti mengisi berita harian diweb dan juga media cetak. Hal itu sangat berdampak pada kualitas jurnalistik yang dihasilkan, sehingga untuk memberikan variasi berita wartawan kesulitan karena waktunya dihabiskan dengan memenuhi kuota harian berita. Kusus media online, wartawan diwajibkan mengisi berita-berita dengan berbagai segementasi seperti news, sport, politik, ekonomi, dan pendidikan, dengan target tertentu. Efek positifnya wartwan akan berkerja dengan berbagai situasi yang akan meningkatkan kemapuaan, namun akan berdampak pada kualitas. Praktik seperti ini mengguntungkan trafik kunjungan media, namun akan memberikan peluang lebih terhadap konten gratis, dengan kata lain praktik paywall tidak akan mampu menghadikan bisnis yang menguntungkan jika ada opsi konten geratis.

Dalam hal ini, berita online mengalami peningkatan jumlah pemirsa, namun, sebagian besar tidak dapat memonetisasi jumlah pembaca yang terus bertambah(Casero-Ripollés dan Izquierdo-Castillo 2013) dalam (Sjovaag, 2015:5). Artinya peningkatan pembaca bukan menjadi sumber utama pendapatan, melainkan dijadikan data untuk menarik iklan, secara langsung media mengadalkan pihak lain untuk mendaptakan keuntungan, dan tidak mungkin semua media memiliki model sama dalam menarik keuntungan. Konten seperti apa yang layak untuk paywall?.

Berita keras dan opini sebagai komoditas berita paling berharga, serta berita teknologi untuk menarik khalayak dalam meningkatkan langganan digital (Myllylahti, 2016:1). Jika lihat kondisi di Indonesia, berita keras memiliki daya tarik tinggi bagi pembaca karena sifatnya informatif, hal itu karena pembaca Indonesia tertarik denga isu-isu yang dekat dengan kondisi sosial masyarakat seperti berita kebakaran, kerusuhan, korupsi, politik, kecelakaan, namun tidak menjadi indikator masyarakat keseluruhan menyukai. Perbedaan kelas sosial juga mempengaruhi bacaan sesorang. Begitujuga dengan berita opini yang mengulas persoalan secara kusus dengan pendekatan akademik dan jurnalisme sastrawi. Berita-berita opini memiliki nilai tersendiri bagi para pembacanya. Jika dilihat dari konten berbayar, kemungkinan 
terbesar yang berlangganan adalah orang yang mampu secara ekonomi. Sehingga berita opini, akan memberikan pengetahuan bahkan untuk refrensi dalam beberapa kasus, seperti isu lingkungan, hukum, politik, ekonomi dan sosial. Pasar ini memungkinkan media, mampu menarik pembaca dari kelas tertentu. Teknologi selalu dikaitkan dengan perkebangan terkini. Artinya anak muda selalu suka dengan perkembangan. Berta tentang teknologi sangat mungkin menarik pembaca anak muda Indonesia yang menyukai perkembangan. Berita tentang otomotif, teknologi elektronik menjadi magnet untuk menarik pembaca.

Penulis menilai, ketiga berita bersebut tidak lengkap jika tidak melibatkan berita investigasi. Poin pentinggnya berita investigasi memiliki nilai lebih dalam memberikan kepuasan pembaca, sehingga berita ini akan sangat ekslusif dalam memberikan berita. Tingkat kerumitan dan proses panjang membuat berita ini akan mampu menarik pembaca dari berbagai segementasi pembaca. Sejauh ini media tempo, secara konsisten menjadikan berita investigasi menjadi ciri khas media, sehingga tinggkat kepercayaan publik tinggi.

\section{Keuntungan Media Online}

Media tidak terlepas dengan adanya iklan sebagai salah satu pemasok pendaptan perusahaan selain berjualan konten. Generasi media sebelumnnya media konvensional menjadikan hubungan transaksional sebagai model bisnis utama, dimana ada barang yang dipertukaran dengan nilai nominal tertentu, termasuk adanya konten yang akan menarik iklan. Perkembangaan selanjutnya, media online tetap mengandalkan iklan sebagai bahan utama pemasukan. Selain iklan, klik dari pembaca juga mempengaruhi pendapatan. Tingginya angka klik dari pembaca akan dimanfatkan bagi pemilikik platfrom untuk menjual kepada pengiklan agar memasangkan iklan didalam media tersebut. Dengan begitu akan memberikan pengaruh besar terhadap pendaptan dan jumlah iklan. Praktik komodifikasi seperti ini banyak dilakukan oleh media online. Sehingga dalam satu layar dua sampai 6 iklan akan terpasang. Saat ini, data stasitisik kunjungan, nilainya sangat tinggi, karena mempengaruhi berbagai bentuk bisnis yang memungkinan setiap pengguna terekam aktifitasnya saat menggunakan internet, mulai kebiasan, kesukaan, dan juga gaya hidup. Perkembangan selanjutan, muncul konsep LongTail, dengan asumsi bahwa budaya dan ekonomi semakin bergeser dari fokus pada sejumlah kecil hit di kepala kurva permintaan dan bergerak menuju sejumlah besar ruang di ekor Anderson (2006) dalam (Cook \& Sirkkunen, 2013:67).

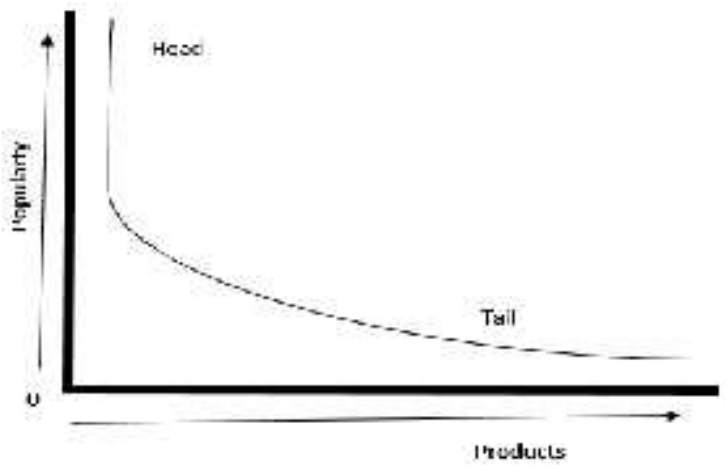

Gambar: long tail 
Praktik media tradisonal hanya berhenti pada popularitas sesaat kemudian perlahan menurun, sehingga nilai dan pangsa pasar dapat diketahui. Model seperti ini sangat efektif dalam media konvensional yang berbatas waktu. Berbeda ketika sekarang internet menguasai berbagai lini bisnis yang menurut Anderson sebagai bentuk distribusi melalui internet, media sosial, dan koneksi seluler yang memungkinkan setiap orang untuk mendistribusikan berita. Sehingga dapat menjangkau konsumen pasar terus terbuka meski sudah bertahun-tahun. Penyedia berita dan informasi memiliki proses produksi dan distribusi namun itu tidak cukup dalam industri jurnalisme (Zhang, 2018:3). Perubahan konten mengalami transformasi mendalam dengan adanya teknologi(Pavlik, 2010:231), mendorong jurnalisme online sangat mengandalkan analisis konten dalam situs web (Steensen, 2011:313). Saat ini Mengakses berita dengan prangkat seluler telah mendapatkan daya tarik dalam kehidupan sehari-hari masyarakat(Westlund, 2013:7), sehingga media menyesuaikan konten sederhana dan menarik dengan harapan pengguna dapat terus melakukan aktifitas kunjungan web.

Media online Indonesia perlu belajar bagaimana praktik long tail ini mampu mendatangkan keuntungan seperti yang dilakukan netflix.com yang fokus pada film dan vedeo bagaimana merubah popularitas menjadi konsep long tail dan terus mendatangkan keuntungan dengan berbagai strategi. Media online di Indonesia dalam merubah nilai tingginya pembaca ke nominal harus mulai mengembangkan strategi meningkatkan konten premium agar dapat di akses dimasa depan.

\section{SIMPULAN DAN SARAN}

Perkebangan teknologi memberikan perubahan mendasar bagi banyak aspek dimedia. Seperti perubahan konten, isu, penggunaan media sosial sebagai daya tarik, penggunaan clikcbait yang menumbuhkan penasaran, tranformasi dalam tampilan media, target dan sasran pembaca, model media, penggunaan data.

Transformasi tersebut menjadi salah satu hal penting dalam bisnis diera konektivitas. Praktik media online secara umum mengandalkan media sosial sebagai strategi menarik pembaca dengan menampilkan foto dan kutipan menarik yang terhubung ke link berita. Data jurnalitik hadir dengan berbagai bentuk untuk memberikan pembeda dengan konten-konten yang ada. Penggunaan teknologi di media Indonesia turut pada kontain dan juga target pembaca.

Keuntungan media masih didapatkan dengan mengandalkan klik dan iklan, meskipun ada upaya membangun konten berbayar namun masih belum optimal dipraktikan hal ini dipengaruhi budya dan kebiasaan masyarakat Indonesia yang menyukai konten geratis. Diera konektivitas media harus lebih kreatif menarik pembaca salah satunya penggunaan infografis, peningatan interaksi dengan pengguna yang berdampak baik pada peningkatan kunjugan web. Data menjadi hal penting untuk memenangkan pesaingan diera digital sehingga aktivitas trafik media menjadi data penting.Peneliti selanjutanya akan lebih menarik mengembakan penggunaan teknologi otomatisasi dalalam produksi konten dan menjelaskan detail model media kolaborasi sebagai bentuk model bisnis dalam menghadapi dunia digital.

\section{DAFTAR PUSTAKA}

Belanche, D., Cenjor, I., \& Pérez-Rueda, A. (2019). Instagram Stories versus Facebook Wall: an advertising effectiveness analysis. Spanish Journal of Marketing - ESIC, 
23(1), 69-94. https://doi.org/10.1108/SJME-09-2018-0042

Brandstetter, B., \& Schmalhofer, J. (2014). Paid Content. Journalism Practice, 8(5), 499-507. https://doi.org/10.1080/17512786.2014.895519

Burgess, J., \& Hurcombe, E. (2019). Digital Journalism as Symptom, Response, and Agent of Change in the Platformed Media Environment. Digital Journalism, 7(3), 359-367. https://doi.org/10.1080/21670811.2018.1556313

Carlson, M. (2015). The Robotic Reporter: Automated journalism and the redefinition of labor, compositional forms, and journalistic authority. Digital Journalism, 3(3), 416431. https://doi.org/10.1080/21670811.2014.976412

Coddington, M. (2015). Clarifying Journalism's Quantitative Turn: A typology for evaluating data journalism, computational journalism, and computer-assisted reporting. Digital Journalism, 3(3), 331-348. https://doi.org/10.1080/21670811.2014.976400

Cook, C., \& Sirkkunen, E. (2013). What's in a niche? Exploring the business model of online journalism. Journal of Media Business Studies, 10(4), 63-82. https://doi.org/10.1080/16522354.2013.11073576

Eldridge, S. A., Hess, K., Tandoc, E. C., \& Westlund, O. (2019). Navigating the Scholarly Terrain: Introducing the Digital Journalism Studies Compass. Digital Journalism, 7(3), 386-403. https://doi.org/10.1080/21670811.2019.1599724

Evens, T., Raats, T., \& von Rimscha, M. B. (2017). Business model innovation in news media organisations-2018 special issue of the European Media Management Association (emma). Journal of Media Business Studies, 14(3), 167-172. https://doi.org/10.1080/16522354.2018.1445164

Fletcher, R., Nielsen, R. K., Fletcher, R., \& Nielsen, R. K. (2016). Paying for Online News PAYING FOR ONLINE NEWS A comparative analysis of six countries. Digital Journalism, 0811(October), 1-19. https://doi.org/10.1080/21670811.2016.1246373

Franklin Bob. (2014). The Future of Journalism. Journalism Studies, (February 2015), 37-41. https://doi.org/10.1080/1461670X.2014.930254

Helle Sjøvaag. (2015). Introducing the Paywall. (April), 37-41. https://doi.org/10.1080/17512786.2015.1017595

Hermida, A. (2010). Twittering the news: The emergence of ambient journalism. Journalism Practice, 4(3), 297-308. https://doi.org/10.1080/17512781003640703

$\mathrm{Https://beritagar.id/artikel/berita/generasi-z-pengguna-internet-terbesar-di-indonesia.}$ (n.d.). Generasi Z, pengguna internet terbesar di Indonesia.

Https://katadata.co.id/berita/2017/12/07/nielsen-pembaca-media-digital-sudah-lampauimedia-cetak. (n.d.). Nielsen: Pembaca Media Digital Sudah Lampaui Media Cetak I Katadata News.

Https://kumparan.com/@kumparannews/kumparan-dan-swa-berkolaborasi-dalaminovasi-media-digital. (n.d.). Bangun Inovasi, kumparan dan SWA Berkolaborasi kumparan.com.

Https://kumparan.com/panturapost/pantura-post-siap-berkolaborasi-dengan-kumparan. (n.d.). Pantura Post Siap Berkolaborasi dengan Kumparan - kumparan.com.

Https://mojok.co/daf/esai/jika-google-mendadak-hilang-dari-dunia-ini-karena-digugatdonald-trump/. (n.d.). Jika Google Mendadak Hilang dari Dunia ini karena Digugat Donald Trump - Mojok.co.

Https://tekno.kompas.com/read/2019/05/16/03260037/apjii-jumlah-pengguna-internet-di- 
indonesia-tembus-171-juta-jiwa. (n.d.). APJII: Jumlah Pengguna Internet di Indonesia Tembus 171 Juta Jiwa.

Https://www.brilio.net/creator/10-media-sosial-ini-paling-banyak-digunakan-oleh-orangindonesia-e5e00f.html. (n.d.). 10 Media sosial ini paling banyak digunakan oleh orang Indonesia.

Https://www.theguardian.com/media/2010/jul/20/times-paywall-readership. (n.d.). Times loses almost $90 \%$ of online readership | Media | The Guardian.

Kim, D., \& Kim, S. (2018). Telematics and Informatics Newspaper journalists ' attitudes towards robot journalism. Telematics and Informatics, 35(2), 340-357. https://doi.org/10.1016/j.tele.2017.12.009

Myllylahti, M. (2014). Newspaper Paywalls - the Hype and the Reality. (February 2015), 37-41. https://doi.org/10.1080/21670811.2013.813214

Myllylahti, M. (2016). What Content is Worth Locking Behind a Paywall ? WHAT CONTENT IS WORTH LOCKING BEHIND A PAYWALL? Digital news commodification in leading Australasian financial newspapers. Digital Journalism, 0811(May). https://doi.org/10.1080/21670811.2016.1178074

Noor, F. (2018). Model Bisnis Media Online Dalam Menghadapi Persaingan. (May).

Pavlik, J. (2000). The Impact of Technology on Journalism. Journalism Studies, 1(2), 229-237. https://doi.org/10.1080/14616700050028226

Pers, J. D. (n.d.). 715-Buku Jurnal Dewan Pers 14 Indonesia.

Rambe, P., \& Jafeta, R. J. (2017). Impact of social media advertising on high energy drink preferences and consumption. Journal of Applied Business Research, 33(4), 653-668. https://doi.org/10.19030/jabr.v33i4.9977

Sætra, H. S. (2019). The tyranny of perceived opinion: Freedom and information in the era of big data. Technology in Society, 59(July), 101155. https://doi.org/10.1016/j.techsoc.2019.101155

Saptya, R., \& Permana, M. (2019). STRATEGI PEMANFAATAN MEDIA BARU NET . TV UTILIZATION OF NEW MEDIA STRATEGY OF NET . TV. 21-36.

Soliha, S. F. (2015). Tingkat Ketergantungan Pengguna Media Sosial Dan Kecemasan Sosial [Level of Dependence on Users of Social Media and Social Anxiety]. Interaksi: Jurnal IImu Komunikasi, 4(1), 1-10. https://doi.org/10.14710/INTERAKSI,4,1,1-10

Steensen, S. (2011). Online journalism and the promises of new technology: A critical review and look ahead. Journalism Studies, 12(3), 311-327. https://doi.org/10.1080/1461670X.2010.501151

Taneja, H., Wu, A. X., \& Edgerly, S. (2018). Rethinking the generational gap in online news use: An infrastructural perspective. https://doi.org/10.1177/1461444817707348

Thurman, J. H. \& N. (2007). PAID CONTENT STRATEGIES FOR NEWS WEBSITES PAID CONTENT STRATEGIES FOR NEWS An empirical study of British newspapers , online business models. (October 2014), 37-41. https://doi.org/10.1080/17512780701275523

Weaver, D. H., \& Willnat, L. (2016). Changes in U.S. Journalism: How do journalists think about social media? Journalism Practice, 10(7), 844-855. https://doi.org/10.1080/17512786.2016.1171162

Westlund, O. (2013). Mobile news: A review and model of journalism in an age of mobile 
media.

Digital

Journalism,

1(1),

$6-26$.

https://doi.org/10.1080/21670811.2012.740273

Zhang, S. I. (2018). The Business Model of Journalism Start-Ups in China. Digital Journalism, O(0), 1-21. https://doi.org/10.1080/21670811.2018.1496025 